\title{
Saúde coletiva nos cursos de Nutrição: análise de projetos político-pedagógicos e planos de ensino
}

\author{
Public Health in the undergraduate Nutrition \\ programs: Analysis of the educational and \\ political projects and teaching plans
}

Elisabetta RECINE ${ }^{1}$

Andrea SUGAI ${ }^{2}$

Renata Alves MONTEIRO'

Anelise RIZZOLO'

Andhressa FAGUNDES 3

RE S U M O

\section{Objetivo}

Este trabalho tem por objetivo analisar os conteúdos dos planos de ensino das disciplinas da área de Nutrição em Saúde Coletiva, bem como os projetos político-pedagógicos de cursos de Nutrição no Brasil.

\section{Métodos}

Trata-se de estudo qualitativo, exploratório, de base documental, utilizando-se técnica do software A/ceste ${ }^{\circledast}$ no corpus gerado pelos documentos analisados.

\section{Resultados}

A partir dos 392 cursos de Nutrição existentes no Brasil em 2010, foram analisados 46 projetos político-pedagógicos e 517 planos de ensino de disciplinas em saúde coletiva. Na análise dos projetos político-pedagógicos foram consideradas três categorias: competências esperadas; ações no cuidado nutricional e operacionalização do curso, esta última correspondente a 75,5\% do conteúdo. Já na análise dos planos de ensino foram classificadas as seguintes categorias: avaliação nutricional, clínica e dietoterapia no curso da vida; epidemiologia nutricional e vigilância em saúde; educação nutricional e comunicação; formação para atuação

${ }^{1}$ Universidade de Brasília, Faculdade de Ciências da Saúde, Departamento de Nutrição. Campus Universitário Darcy Ribeiro, Núcleo de Medicina Tropical e Nutrição, Sala 9C, 70910-900, Brasília, DF, Brasil. Correspondência para/Correspondence to: E RECINE.E-mail: <recine@unb.br>.

2 Universidade Federal de Goiás, Faculdade de Nutrição. Goiânia, GO, Brasil.

${ }^{3}$ Universidade Federal de Sergipe, Departamento de Nutrição. São Cristóvão, SE, Brasil.

Apoio: Ministério da Saúde (Processo no 25000207801/2008-91, Convênio: 667/2008-2011). 
profissional; e cultura e ciências sociais. A primeira dessas categorias, correspondente a 34,2\% do conteúdo, representa um dos eixos do corpus: portanto, a que compõe mais fortemente a disposição dos elementos. Essa categoria demonstrou abordar temas distantes daqueles tratados pelas demais. O outro eixo, das demais classes, estabeleceu associação menos distante no plano entre elementos, refletindo existir alguma ligação entre o que é explicitado e objetivos, conteúdos e processo de formação que correlacionam alimentação ao contexto social e à prática profissional.

\section{Conclusão}

A distância dos conteúdos analisados indica uma dicotomia ao se descreverem objetivos, competências e prática profissional, apontando a insuficiência na articulação entre os elementos biológicos, as práticas sociais e a formação profissional.

Termos de indexação: Educação superior. Prática profissional. Saúde Pública.

\section{A B S T R A C T}

\section{Objective}

To analyze the contents of the teaching plans of the disciplines in the areas of Nutrition in Public Health and political and educational plans of nutrition programs in Brazil.

\section{Methods}

This is a qualitative, exploratory, document-based study that used the technique of the software Alceste ${ }^{\circledR}$ in the corpus generated by the analyzed documents.

\section{Results}

Of the 392 nutrition programs available in 2010 in Brazil, we collected 46 political and educational plans and 517 teaching plans of disciplines in public health. The categories classified and generated for the political and educational plans were: expected competences; actions in nutritional care; and operationalization of the program. The third category corresponded to $75.5 \%$ of the content given that much of the content is related to the operationalization of the programs. The categories classified in the second analysis regarding the teaching plans were: nutritional and clinical assessment and diet therapy throughout life; nutritional epidemiology and health surveillance; nutrition education and communication; education for professional practice and culture and social sciences. The first category of this stage corresponded to $34.2 \%$ and to one of the axis of the corpus: therefore, the one that composes the disposition of the elements more strongly. This category approached themes little related to the themes treated by the other categories. The other axis of the other classes established a less distant association in the plane between elements, showing that there is some connection between what is exposed and the objectives, contents, and education process that correlate food with the social context and professional practice.

\section{Conclusion}

The distance between the analyzed contents indicates a dichotomy when describing objectives, competences, and professional practice. The coordination between the biological elements, social practices, and education is inadequate.

Indexing terms: Education, higher. Professional practice. Public Health.

\section{N T R O D U ÇÃ O}

As recomendações e processos que envolvem a formação do nutricionista preconizam um profissional com formação generalista, humanista e crítica que, pautado por princípios éticos e refletindo sobre a realidade econômica, política, social e cultural das comunidades, tenha como objetivo de sua atuação, por meio da alimentação, contribuir para a melhoria da qualidade de vida e saúde dos indivíduos e coletividades ${ }^{1}$.

Frente a essas diversas dimensões construídas histórica e politicamente, consideradas necessárias para atuar em alimentação e nutrição, um dos questionamentos em relação aos cursos de nutrição refere-se à qualidade do processo de 
formação, considerando que os aspectos biológicos são hegemônicos e, portanto, privilegiados em detrimento da multideterminação dos problemas alimentares e nutricionais². Associado a isso, um dos desafios tem sido reconhecer quais são as habilidades e competências necessárias ao nutricionista diante das diferentes dimensões exigidas para atuar em alimentação e nutrição ${ }^{3}$.

Dessa maneira, torna-se relevante verificar como tem se dado o alinhamento e a articulação entre os projetos político-pedagógicos dos cursos de nutrição e os planos de ensino de disciplinas da área de saúde coletiva, tendo em vista a formação do nutricionista. Essa averiguação vem ao encontro da proposta de educadores e profissionais que buscam, frente aos muitos desafios impostos nesse campo de atuação em saúde, diminuir as lacunas educacionais, principalmente devido a currículos que geram profissionais recém- graduados mal preparados para os desafios cognitivos, políticos institucionais e para a atuação prática, dentre outros aspectos ${ }^{4}$.

Os projetos político-pedagógicos constituem uma ferramenta de planejamento e avaliação, cujas propostas visam: descrever ações a executar durante um período de tempo (plano ou projeto); considerar a instituição como um espaço de formação de cidadãos conscientes, responsáveis e reflexivos, que atuarão individual e coletivamente na sociedade (político); e definir e organizar atividades e projetos educativos necessários aos processo de ensino e aprendizagem (pedagógico). Por sua vez, o plano de ensino da disciplina é um instrumento didático-pedagógico e administrativo, compreendido por ementa, objetivos, conteúdo programático e organização da disciplina ${ }^{5-7}$.

A atuação do nutricionista, em todos os campos de ação, tem sido desafiada frente às características do sistema alimentar e dos modos de vida contemporâneos. De maneira mais específica, esses elementos têm gerado um cenário sócio-sanitário no qual a condição alimentar-nutricional vem ganhando destaque como questão de Saúde Coletiva ${ }^{1-3}$ e exigindo uma atuação mais ampla e qualificada do profissional. Porém, entendendo a alimentação e nutrição em saúde coletiva como um campo multidimensional, como elaborado por Bosi \& Prado ${ }^{3}$, apesar desse crescente destaque, as questões que envolvem a formação dos nutricionistas para o desenvolvimento de ações sistemáticas e estratégicas nessa área têm sido insuficientemente abordadas, tanto em caráter nacional quanto internacional ${ }^{4-6}$.

Em termos gerais, o trabalho do nutricionista em saúde coletiva reúne um conjunto de desafios, dentre os quais ${ }^{1-4,7,8}$ a análise dos problemas, considerando a determinação social da saúde e da alimentação e nutrição; a escolha de estratégias de ação baseadas em evidências e efetividade; a compreensão da abrangência desse campo de conhecimentos, saberes e práticas em suas relações com a saúde coletiva e as demais ciências; e a tradução do conhecimento em prática ampla e efetiva, principalmente na atenção básica do Sistema Único de Saúde.

De maneira a contribuir para a definição de medidas endereçadas à superação desses desafios, o presente estudo se propõe a analisar planos de ensino das disciplinas da área de nutrição em saúde coletiva e projetos político-pedagógicos de cursos de nutrição no Brasil.

\section{MÉ T O D O S}

Trata-se de um estudo qualitativo, exploratório e descritivo, de base documental proveniente dos dados primários do "Estudo de avaliação da formação do profissional nutricionista e seu alinhamento com as políticas de saúde no Brasil" " financiado pelo Ministério da Saúde, de caráter transversal, tipo survey.

Para compor o quadro de participantes da pesquisa foi inicialmente realizado o convite a todas as instituições públicas e particulares do país que ofereciam cursos de graduação em Nutrição. Como critério de inclusão, as instituições deveriam possuir turma formada até o término do primeiro semestre de 2010 e disponibilizar os projetos 
político-pedagógicos e os planos de ensino das disciplinas na área de Nutrição em Saúde Coletiva vigentes para aquele mesmo ano. Foram excluídas as instituições que não se adequavam a esses requisitos. Foi necessária a atualização na base de dados das escolas de Nutrição do País, disponibilizada pelo Conselho Federal de Nutricionistas (CFN), o que foi realizado mediante contato telefônico, mensagem eletrônica e sítio eletrônico, com o intuito de identificar os coordenadores dos cursos e, consequentemente, minimizar a taxa de não resposta. O cadastro inicial indicava a existência de 392 escolas de Nutrição em 2010, das quais 55 públicas (14\%).

Os convites foram enviados por meio eletrônico aos coordenadores dos cursos, contendo carta de apresentação do estudo e Termo de Consentimento Livre e Esclarecido (TCLE). O mesmo também foi divulgado extensivamente em sítios eletrônicos de instituições parceiras, como o Conselho Federal de Nutricionistas, o Conselho Nacional de Segurança Alimentar e Nutricional e a Coordenação Geral de Alimentação e Nutrição do Ministério da Saúde, conclamando os coordenadores de curso a atualizarem seus dados junto à coordenação da pesquisa. De maneira complementar, durante o período da coleta, entre setembro de 2009 e fevereiro de 2010, foram realizadas ligações telefônicas aos coordenadores de cursos. A pesquisa foi aprovada pelo Comitê de Ética em Pesquisa da Faculdade de Ciências da Saúde da Universidade de Brasília, Registro 97/2009.

Após a atualização e aplicado o primeiro critério de exclusão, o universo amostral ficou composto por 296 (75,5\%) cursos, dos quais 46 eram instituições públicas. Porém, após a aplicação do segundo critério de exclusão - o envio do projeto político-pedagógico e dos planos de ensino de disciplinas na área de nutrição em saúde coletiva -, os dados da pesquisa disponibilizados foram de 46 instituições $(11,7 \%)$. Dessa maneira, a análise consistiu de 46 projetos político-pedagógicos. Das instituições participantes, 18 (39,0\%) eram públicas e $28(61,0 \%)$ privadas. Quanto à região, 2 instituições (4,3\%) estavam localizadas na Região Norte, $3(6,5 \%)$ na Região Nordeste, 8 $(17,4 \%)$ na Região Centro-Oeste, 21 (45,7\%) na Região Sudeste e $12(26,1 \%)$ na Região Sul. Do total de 392 instituições existentes em 2010, $32,7 \%$ (18 de 55 ) dos dados foram provenientes das universidades públicas e 8,3\% (28 de 337) de instituições privadas.

As disciplinas que compõem a área de Nutrição em Saúde Coletiva disponibilizadas pelas ementas foram agrupadas segundo denominação ou conteúdo em: educação nutricional, avaliação nutricional, alimentação e cultura, antropologia, bioestatística, economia, epidemiologia, estágio em nutrição em saúde pública, nutrição em geriatria, nutrição e saúde da família, nutrição em saúde pública, nutrição materno-infantil, nutrição do adolescente, nutrição e fases da vida, nutrição e marketing, políticas públicas de nutrição, políticas públicas de saúde, práticas de atendimento ambulatorial, prática de saúde, princípios da comunicação e outras. A análise consistiu de 517 planos de ensino de disciplinas na área de Nutrição em Saúde Coletiva.

Foi utilizado como ferramenta o software Analyse Lexicale par Contexte d'un Ensemble de Segments de Texte (Alceste ${ }^{\circledast}$, Análise Lexical de Correspondência em Enunciados Simples de um Texto), criado em 1986 pelo pesquisador francês Max Reinert e desenvolvido e distribuído pela sociedade IMAGE ${ }^{10}$. O instrumento foi elaborado a partir do pressuposto de que diferentes opiniões de instituições/sujeitos produzem diferentes maneiras de abordar um determinado tema.

O Alceste ${ }^{\circledast}$ foi utilizado para análise distinta de cada um dos dois documentos (corpus de textos) desta pesquisa.

Enquanto técnica, o Alceste ${ }^{\circledR}$, por meio de repetições e sucessões de palavras, investiga a distribuição de vocábulos de um corpus de textos, buscando distinguir classes de palavras que representem formas relevantes e distintas sobre o tema de interesse a ser investigado ${ }^{11,12}$. Nesse sentido, a análise de um vocabulário específico poderia ser utilizada como fonte para apreender formas diversas de pensar sobre um dado objeto ${ }^{11}$. 
A relação epistemológica dessa técnica com a Teoria das Representações Sociais (TRS) embasou a pesquisa. Segundo Moscovici'i3, as representações sociais são hipóteses explicativas sobre objetos/instituições socialmente relevantes, construídas por conexões de sentidos em uma dinâmica de reinterpretação, constituição e mudança.

Como metodologia, configura-se um método de descrição e exploração, uma vez que agrega uma significativa quantidade de sofisticados métodos estatísticos que propiciam a segmentação do texto em fragmentos menores, a classificação hierárquica e análise fatorial de correspondências, além de outros recursos, produzindo resultados passíveis de interpretação ${ }^{11,12}$.

O programa realiza uma análise léxica das palavras no conjunto dos textos, em quatro etapas, consistentes em ${ }^{12,14,15}$.

a) Leitura dos documentos e cálculo dos dicionários de formas reduzidas. Na preparação do corpus desta pesquisa, destaca-se a atenção dada para os materiais usados em sua elaboração, os quais foram divididos por tema específico, como garantia da homogeneidade, relevância e sincronismo ${ }^{12,16}$. Nessa perspectiva, foram definidas como Unidades de Contexto Inicial (UCI) os projetos político-pedagógicos e os planos de ensino. O conjunto de $\mathrm{UCl}$ constitui o corpus de análise ou o conjunto de todos os dados num único arquivo ${ }^{17}$. Na formatação não foi permitido o uso de aspas, percentagens, apóstrofos e asteriscos, por serem considerados caracteres específicos não universais. Esses caracteres foram substituídos, levando-se em conta a limitação do dicionário ${ }^{11,14,16}$. Nesse sentido, na preparação do corpus não foram utilizados artigos, conjunções, numerais, pronomes, verbos auxiliares nem advérbios. Foi realizada uma reformatação do texto, com uma posterior apresentação em formato de lista do vocabulário do corpus, mediante o cálculo de frequência, em ordem alfabética, e foi gerado um dicionário de formas reduzidas. Foi por meio dessas formas reduzidas que o programa efetuou as suas análises. b) Definição e seleção das Unidades de Contexto Elementar (UCE) e Classificação Hierárquica Descendente (CHD). A segmentação do texto em fragmentos menores gerados para análise, denominadas Unidades de Contexto Elemen$\operatorname{tar}$ (UCE), foi definida pelo programa de forma aleatória. A segmentação se baseia no critério de tamanho do texto (com um intervalo sequencial aproximado de três linhas ou 8 a 10 palavras e/ou, ainda, um trecho do texto). A classificação das UCE ocorre em função do agrupamento dos trechos que compartilham o mesmo vocabulário. No momento subsequente, foi feita a divisão do conjunto de UCE em função da frequência das formas reduzidas, e constituídas as matrizes com o objetivo de obter a separação das UCE que se diferenciavam. A partir dessas matrizes, aplicou-se o método de CHD, o qual apresenta a organização do texto em diferentes classes que abordem um mesmo tema ou assunto ${ }^{11,12,17}$. Dessa maneira, o programa computou, para cada categoria, por meio do Teste Qui-quadrado $\left(\chi^{2}\right)$, uma lista de palavras características dessa mesma classe, revelando a força associativa entre cada palavra e sua categoria. Dessa maneira, quanto maior o $\chi^{2}$ correspondente à palavra, mais significativa é sua presença para a categoria ${ }^{11}$. A leitura das palavras reduzidas mais significativas, as palavras ausentes e as UCE mais características de cada classe ou as listas geradas - todas classificadas em função e em ordem decrescente do $\chi^{2}$-, possibilitaram a interpretação semântica dos dados pela equipe, considerando o conhecimento do campo conceitual delineado ${ }^{11,14,17}$.

c) Descrição das classes estabilizadas. Nessa etapa, foi configurada a Análise Fatorial de Correspondência (AFC), por meio dos cálculos efetuados na fase anterior, que possibilitaram as descrições de cada classe. Nessa fase da análise são produzidos os esquemas figurativos e apresentados em um plano fatorial, onde se configura o campo representacional. Essa representação espacial das variáveis, compostas por eixos, um horizontal e outro vertical, linhas $x$ e $y$, compondo quatro partes iguais da mesma figura, permitiu a 
análise das relações entre as classes, bem como a verificação de possíveis oposições e complementaridade entre as mesmas ${ }^{11,12,14,17}$.

d) Cálculos complementares. Nessa etapa da análise foram geradas as UCE mais características e os segmentos de frases mais repetidos de cada categoria. A Classificação Hierárquica Ascendente (CHA) - constituída por meio da intersecção entre as UCE das classes e as formas reduzidas significativas e, portanto, características da mesma classe -, permitiu a visualização da organização interna e da relação entre as palavras mais significativas de cada classe. Nesse sentido, a CHA auxiliou na compreensão dos sentidos dos contextos desses termos, bem como na análise da inter-relação entre eles ${ }^{11,12,14,17}$.

\section{RESULTADOS}

\section{Os projetos político-pedagógicos nos cursos de Nutrição}

De acordo com a Classificação Hierárquica Descendente CHD do corpus de análise dos projetos político-pedagógicos, foram formadas três classes: competências esperadas, ações realizadas no cuidado nutricional e operacionalização do curso. Houve baixa relação entre as classes (Figura 1): a relação da classe 1 com as demais foi nula, e entre as classes 2 e 3 foi de 15,0\%. Outro dado relevante é que a classe 3 foi expressivamente maior que as duas outras, correspondendo a 75,5\% do conteúdo analisado.

A Figura 2 reflete a composição de cada uma das classes, com algumas de suas palavras características, bem como a força associativa entre cada palavra e sua classe. As palavras que apresentaram maior força associativa com a classe 1 (as palavras de maior $\chi^{2}$ ) podem ser consideradas como ideias associadas às competências esperadas para o graduado em Nutrição, bem como palavras que qualificam competências (quanto a seu âmbito ou mesmo forma de aplicação). Destaca-se a presença de verbos como avaliar, planejar, atuar, supervisionar, bem como prescre-

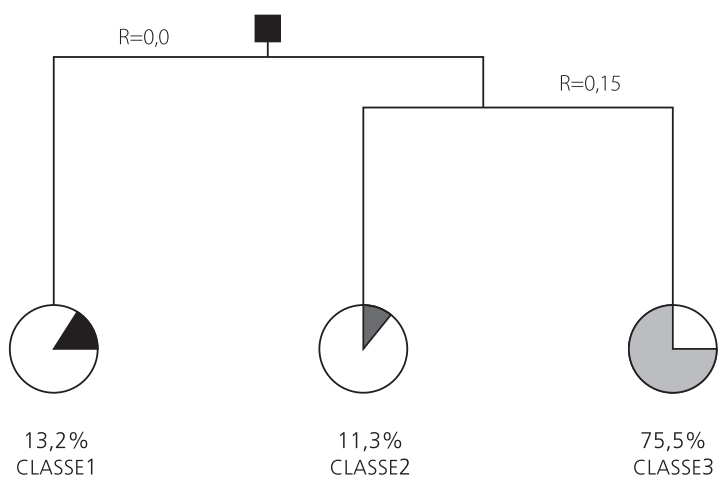

Figura 1. Classificação Hierárquica Descendente do corpus de análise dos Projetos Político-Pedagógicos. Brasil, 2010.

Nota: De acordo com a classificação hierárquica descendente do corpus de análise dos projetos político-pedagógicos, foram formadas três classes: competências esperadas (classe 1), ações realizadas no cuidado nutricional (classe 2) e operacionalização do curso (classe 3), esta última expressivamente maior $(75,5 \%)$.

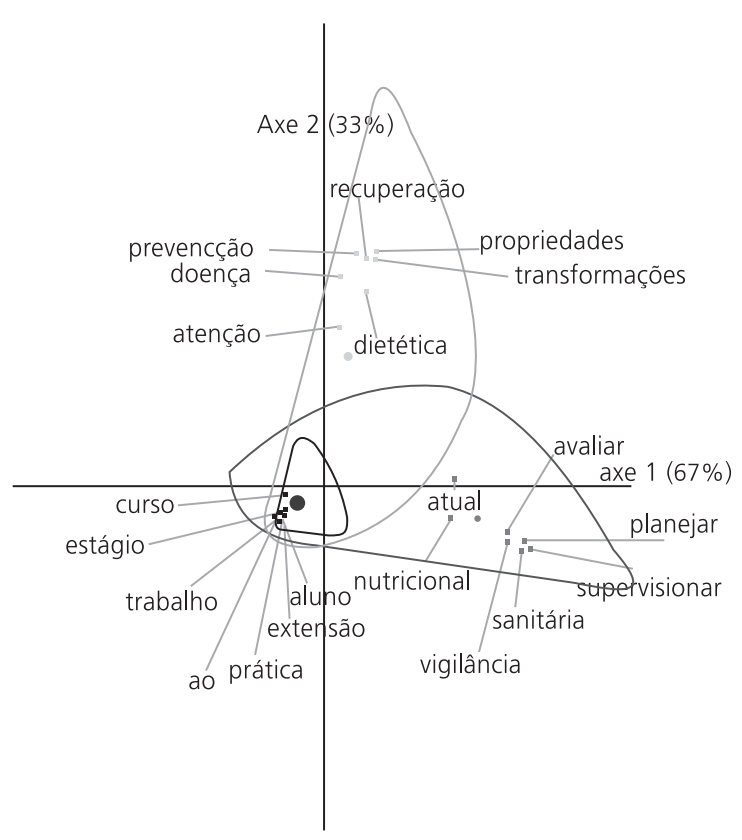

Figura 2. Análise fatorial em coordenadas do corpus de análise dos Projetos Político-Pedagógicos. Brasil, 2010.

Nota: A figura reflete a composição de cada uma das classes (classe 1: competências esperadas; classe 2: ações realizadas no cuidado nutricional e classe 3: operacionalização do curso), com algumas das suas palavras características, ressaltando a força associativa entre cada palavra e sua classe. Ressalta-se que as três categorias estabelecem pouca relação entre si. 
ver, diagnosticar, gerenciar, executar, acompanhar, implementar e analisar. Outras palavras, consideradas como características dessa classe, referem-se especificamente à área de Nutrição: nutricional, sanitária, vigilância, bem como alimentação, consumo, suplementos, dietético, dieta e alimentar, dentre outras.

Por meio da Classificação Hierárquica Ascendente da classe 1 (competências esperadas), foram constituídos três grupos de palavras que se organizam conjuntamente entre as mais significativas de cada classe. Um primeiro arranjo de palavras se refere a: (1) utilização dos alimentos, relacionada ao consumo; (2) influência econômica e biológica; e (3) disponibilidade para determinada população. As palavras realizar e diagnóstico acompanham esse arranjo, relacionando-se ainda com alimentação do indivíduo.

No segundo grupo, a díade enfermo-sadio está relacionada às ações de prescrever, diagnosticar, acompanhar e também aos termos estado, dieta e dietético. $\mathrm{O}$ ato de executar está relacionado com a equipe multiprofissional, assim como são apresentadas as ideias de gerenciar e condições das coletividades conjuntamente. Além dos verbos já mencionados, compõem esse grupo de palavras os verbos planejar, avaliar e supervisionar.

Por fim, nessa mesma classe, tem-se o terceiro grupo constituído pelas palavras nutricional e saúde, relacionadas com os termos atuar em programas de educação alimentar e em vigilância sanitária, tanto em âmbito local e regional quanto nacional. As palavras significativamente ausentes que apresentaram maior força associativa com a classe 1 (as palavras de maior $\chi^{2}$ ) foram: curso, conhecimento, formação, profissional e aluno. Outras palavras ausentes são: estágio, objetivo, realidade e curriculares, dentre outras.

Se para a classe 1 foram característicos os verbos associados às competências esperadas, a classe 2 (ações realizadas no cuidado nutricional) é caracterizada por diversos substantivos como prevenção, recuperação, atenção, transformações, bem como promoção, reabilitação, manutenção e proteção, dentre outras. Outras palavras como dietética, propriedades, doença, bem como grupo, populacionais, composição, fundamentais e organismo, dentre outras, têm também presenças significativas.

Pela análise do contexto interno, a qual permite constatar a organização e a relação entre as palavras mais significativas da classe 2 , observa-se que há a presença do termo gerais, referindo-se à ideia de estar apto à proteção e à reabilitação, tanto no âmbito individual quanto no coletivo. Juntamente com essa primeira ideia, seguem os termos prevenção e promoção. Surgem também termos referentes a estar pautado pela reflexão a partir dos princípios éticos, contribuindo para a melhoria da qualidade de vida. O termo cultural, também presente, provavelmente reforça o termo reflexão, referindo-se principalmente ao contexto cultural. O termo doença é acompanhado por manutenção e recuperação, associado aos grupos populacionais, bem como a toda a atividade em que nutrição e a alimentação se apresentem como fundamentais.

Ainda na análise da classe 2 , outras palavras do corpus remetem à ideia de que se deve formar profissionais capacitados, generalistas e humanistas. Nesse mesmo contexto, é citada também a atenção dietética, garantida por meio do conhecimento, e a sua aplicação/realização por meio de transformações, composições e propriedades dos alimentos e seu aproveitamento pelo organismo humano. Estão ausentes os termos aluno e outros associados mais diretamente à operacionalização do curso de graduação, como extensão, pesquisa, trabalho, estágio, disciplina, prática, projeto, atividade, ensino, curricular e acadêmico, dentre outros. De forma geral, a ausência característica parece mesmo ser relativa a termos que descrevem as atividades do curso de Nutrição e a termos relacionados.

A classe 3, operacionalização do curso, concentrou a ocorrência da maior parte das palavras significativas, correspondendo a $3 / 4$ do corpus de análise. Algumas das palavras com presença significativa nessa classe - como curso, aluno, extensão, trabalho, prática, pesquisa, disciplina, 
projeto, curricular - estão relacionadas propriamente ao curso de graduação em Nutrição, a sua rotina, procedimentos e componentes. Por esse motivo, tais elementos correspondem à maioria dos projetos político-pedagógicos analisados. Tratam da operacionalização e da descrição dos cursos, separados da listagem referente às competências esperadas ou aos objetivos do curso.

Por meio da classificação hierárquica ascendente da classe 3, há a constituição de grupos de palavras que se organizam conjuntamente entre as mais significativas de cada classe. Um primeiro arranjo de palavras se refere a participação, a qual está relacionada à tríade ensino-pesquisa-extensão. Tal participação é também participação em outras atividades científicas, características esperadas nos ambientes das faculdades/universidades. Outro arranjo presente é a integração com a sociedade, a articulação entre esta e a comunidade acadêmica, relacionada ainda com o desenvolvimento científico. Ainda nessa classe são encontradas organizações conjuntas do termo aluno acompanhado de atividades práticas, no contexto da atenção, mas também associado a disciplinas curriculares e estágio supervisionado, bem como estudos e outras atividades complementares ao currículo. Ou seja, remete às estratégias curriculares referentes ao curso (atividades práticas, disciplinas, estágio) e ao que se deve fazer. O termo formação é relacionado com palavras como projeto pedagógico, processo, curricular e trabalho de conclusão de curso.

\section{Os planos de ensino de disciplinas em saúde coletiva dos cursos de Nutrição}

As categorias classificadas na segunda análise, referentes aos planos de ensino das disciplinas foram: (1) avaliação nutricional, clínica e dietoterapia no curso da vida; (2) epidemiologia nutricional e vigilância em saúde; (3) educação nutricional e comunicação; (4) formação para atuação profissional e (5) cultura e ciências sociais. Ou seja, a análise foi sintetizada em cinco cate- gorias, que representam cinco temas ou discursos que permeiam os planos de ensino, estruturadas em dois eixos, $x$ e $y$.

A partir dessa disposição fatorial, foi observado que a primeira categoria, constituída por disciplinas como avaliação nutricional e outras que tratam de contextos específicos ao longo do curso da vida, correspondeu a 34,2\% (Figura 3) e a um dos eixos do corpus. Essa categoria teve relação nula com as demais: quanto mais distantes os elementos dispostos estiverem no plano, menos eles tratam das mesmas coisas, ou seja, a primeira categoria aborda temas distantes daqueles tratados pelas outras classes.

O outro eixo, formado pelas demais classes, estabeleceu associação menos distante no plano entre os elementos, refletindo existir alguma ligação entre o que é explicitado e os objetivos, conteúdos e processo de formação, que correlacionam a alimentação ao contexto social e à prática profissional.

A classe 1 (avaliação nutricional, clínica e dietoterapia no curso da vida) contém palavras

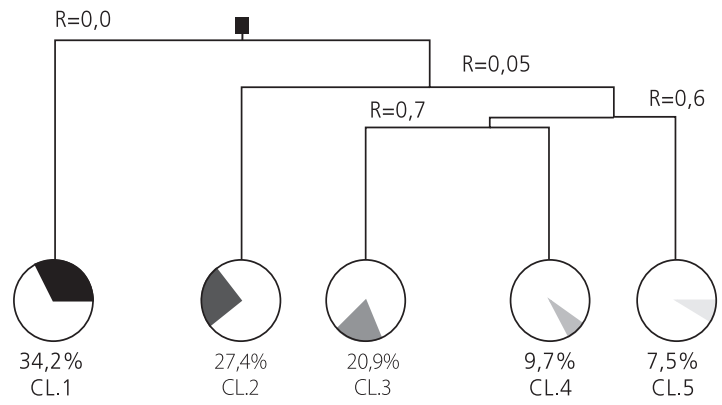

Figura 3. Classificação Hierárquica Descendente do corpus de análise dos planos de ensino das disciplinas da área de Nutrição em Saúde Coletiva. Brasil, 2010.

Nota: As categorias classificadas na segunda análise, referentes aos planos de ensino das disciplinas, foram: (1) avaliação nutricional, clínica e dietoterapia no curso da vida; (2) epidemiologia nutricional e vigilância em saúde; (3) educação nutricional e comunicação; (4) formação para atuação profissional e (5) cultura e ciências sociais. A primeira categoria, formada por disciplinas como avaliação nutricional e aquelas que tratam de contextos específicos abordados nas fases do curso da vida, correspondeu a 34,2\% e a um dos eixos do corpus: portanto, a que compõe mais fortemente a disposição dos elementos. $\mathrm{Cl}$. : Classe. 
como avaliação, clínica, composição e dieto-terapia, bem como gestação, materno, lactente, adulto e adolescência, as quais apontam para o contexto ou ramo específico desse tipo de atuação. Com base na classificação hierárquica ascendente, observa-se que esta é formada por dois grandes conjuntos de palavras, o primeiro englobando os termos clínica e materno, e o segundo com os termos gestante e bioquímico. Desse modo, ambos os grupos possuem subdivisões análogas que corroboram a divisão geral entre palavras referentes a atividades que envolvem a prática e seus contextos específicos. O termo clínica se correlaciona com palavras que intercalam a noção de contextos específicos como avaliação, dietoterapia e composição, ou seja, as palavras mais significativas dessa classe mantêm relação prioritária entre si, mostrando ser uma classe bastante coesa e com pouca dispersão. O termo saúde é um dos que apresentam menor associação com essa classe, com menor $\chi^{2}$.

No que se refere às disciplinas mais vinculadas a essa classe, verifica-se que avaliação nutricional é a disciplina que mais definiu a classe 1. Por outro lado, o conteúdo veiculado por essa disciplina esteve associado a outras como nutrição, materno, infantil, nutrição do adolescente e nutrição e geriatria. As disciplinas referentes a epidemiologia, educação nutricional e nutrição e saúde coletiva são as que menos estão associadas a essa classe. Ou seja, essas disciplinas ou não tratam dos temas das outras ou a forma de sua apresentação nos planos de ensino não promove essa correspondência. Não há assim coincidência de vocábulos no que diz respeito ao número de ocorrências e similitudes de cada raiz léxica utilizada, de modo que as disciplinas apontam elementos discursivos distintos.

No segundo eixo está a classe 2, referente à epidemiologia e à vigilância em saúde (Figura $3)$, que se relaciona de forma fraca com as classes 3 , 4 e $5(R=0,35)$. No entanto, a classe 5 (cultura e ciências sociais) apresentou grau de relação acima da média $(R=0,6)$. Essa classe ainda se relaciona com as classes 3 e 4, respectivamente referentes à formação para atuação profissional e à educação nutricional e comunicação $(R=0,7)$.

Observa-se, na Figura 3, que as classes 2, 3, 4 e 5 estão relacionadas, refletindo associação entre o elemento discursivo e os objetivos, conteúdos e processo de formação. Há um distanciamento das classes 4 e 5 - menos específicas e mais relacionadas com as demais -, em relação à classe 1, e um pouco menos em relação à classe 2. A Classe 4 apresenta um dos menores volumes dentre as classes $(9,8 \%$ do total do corpus analisado) e não apresenta grande especificidade, ou seja, correlaciona mais temas com as demais classes. Obviamente, os temas correlacionados não são os mais centrais dessa classe, porém evidencia seu distanciamento, em termos de vocabulário, em relação às duas primeiras classes, mesmo em termos mais periféricos.

A classe 2 tem como termo epidemiologia, epidemiológica, epidemiológico, além de outros que dizem respeito a sistema, relacionado à males como fome, desnutrição e doença no que se referem ao Brasil. Essa perspectiva ampla, epidemiológica de fato, é corroborada por termos como política, nacional, país, na sua amplitude; e por vigilância, segurança, saúde, na sua temática. Grande parte das palavras mais características dessa classe estão ausentes na classe 1, exaltando a separação entre os dois eixos formados pela classe 1 e pelas demais classes de forma independente.

O termo política está fortemente vinculado à política de segurança alimentar e nutricional, assim como o termo sistema está ligado de forma acentuada a único, em uma referência ao Sistema Único de Saúde (SUS). Os problemas de saúde pública também fazem parte dessa classe, bem como a vigilância (que aparece ligada à política de segurança alimentar). Relacionado a esse conjunto de palavras, termos como epidemiologia descritiva, indicadores epidemiológicos, transição estão relacionados à questão do saneamento ambiental. Nessa classe, as disciplinas de nutrição e saúde coletiva e de epidemiologia compartilham de um mesmo aspecto discursivo, ou seja, os te- 
mas e a forma como são tratados se aproximam. De fato, essa classe é comum às duas variáveis e, nesse sentido, o tema aqui tratado é partilhado de forma bastante similar. Por outro lado, as disciplinas de avaliação nutricional, clínica e dietoterapia no curso da vida ou contextos específicos e educação nutricional são as que estão significativamente ausentes nessa classe.

A classe 3 (educação nutricional e comunicação) está relacionada em um grau elevado $(R=0,6)$ com as classes 4 e 5 (respectivamente, "formação para atuação profissional" e "cultura e ciências sociais"). Essa classe é caracterizada por palavras relacionadas ao processo educativo, como educação, ensino, educativo, educativa, educador, ensino e aprendizagem. Alguns outros termos como comunicação, comportamento, fundamento, cognitivo e hábito complementam o sentido da classe. Ferramentas, materiais, planejamento, audiovisuais, pirâmide são palavras que podem estar associadas ao processo educativo e que compõem a lista de palavras mais significativamente presentes na classe. A palavra comunicação se relaciona tanto com técnica quanto com teoria, fazendo a ligação também com o termo educação - geralmente abordada no que diz respeito à educação nutricional. Já os materiais a que se faz referência são sobretudo didáticos e se relacionam com as práticas pedagógicas. As classes 3 e 4 estão relacionadas em um grau elevado $(R=0,7)$, ou seja, apresentam associação menos distante, refletindo existir ligação entre o que é explicitado e os objetivos, conteúdos e processo de formação, que correlacionam a alimentação ao contexto social e à prática profissional.

A classe 4 (formação para atuação profissional) tem como vocábulo mais específico o termo nutricionista, seguido de atuação, área e profissional. Outros termos seguem a mesma linha, como atividade, trabalho, profissionais, ações, atribuição, aplicação, entre outros. As palavras atribuições e vivência mantêm relação de exclusividade com essa classe, só aparecendo nessa categoria. Termos como conhecimento e crítica são palavras que aparecem, agregando vocábulos propositivos para atuações e atribuições dentro da classe 4. Equipe e vivência são outros termos com presença significativa. Ou seja, o conjunto de palavras detalha as ações esperadas nessa formação visando à atuação. Tal formação é traduzida em ações como analisar, refletir, planejar e identificar, de forma a vincular à realidade local as intervenções, garantindo-se como preceito que, tais ações devem se basear nos parâmetros gerais da atuação profissional delimitada no conjunto anterior de palavras.

O conteúdo dos vocábulos da classe 5 diz respeito à presença da cultura e das ciências sociais nos cursos de Nutrição, sendo referentes tanto à antropologia quanto à sociologia. Dessa forma, palavras como cultura-cultural, sociedade-social-sociais se destacam por sua ligação com essa classe, assim como corpo, comida, poder, ciência, assuntos tratados por esses dois ramos do conhecimento. As duas primeiras palavras, cultura e sociedade, estão relacionadas a termos como corpo e comida, demonstrando o uso e possível entendimento de tais palavras no contexto da classe e das disciplinas associadas a ela. Mesmo no caso dos termos cultura e sociedade, as informações corroboram esse aspecto introdutório e explicativo dos planos de ensino. Cabe destacar que a classe 5 é a de menor tamanho em volume de texto, o que significa que o conteúdo trazido nos planos de ensino foi pouco referente ao assunto tratado por essa classe.

\section{DISCUSSÃO}

Os dados da pesquisa - constituída por 46 projetos político-pedagógicos e 517 planos de ensino, correspondentes a 11,7\% das instituições -, possibilitam uma interpretação geral, sinalizando a tendência formativa do conjunto dos cursos analisados, não podendo, no entanto, ser extrapolados para todos os cursos do país.

Por meio deste estudo, observou-se que a maior parte de todo o conteúdo veiculado nos projetos político-pedagógicos analisados diz res- 
peito à operacionalização dos cursos. Dessa maneira, mais que evidenciar a distância topográfica entre os conteúdos na estrutura dos projetos político-pedagógicos, essa separação indica que os termos utilizados para descrever os objetivos e/ou as competências do curso são diferentes dos termos utilizados para a descrição do curso em si. Observa-se que a intencionalidade das escolhas e as seleções efetuadas nos projetos político-pedagógicos contêm menos informação sobre o que o profissional é e faz ${ }^{6,8}$, e mais informações de cunho operacional e descritivo.

Um fato a ser ressaltado é que a formação de uma categoria com tal amplitude e tamanho não deve ser encarada como uma deficiência, nem como uma limitação da análise. Pelo contrário, tal resultado se dá porque o conteúdo dessa categoria demonstra estar difuso por todo o corpus de análise. Há, portanto, uma predominância de tais elementos na maioria dos projetos político-pedagógicos analisados. Tratam da operacionalização e da descrição dos cursos, separados da descrição das habilidades e competências a serem desenvolvidas ou dos objetivos do curso. Desse modo, conforme apontado pelas análises dos planos de ensino das disciplinas na área de nutrição em saúde coletiva, a descrição dos cursos de Nutrição, de acordo com seus projetos políticopedagógicos, apresenta, quase em sua maioria, a mesma forma para tratar de alguns poucos conteúdos que se diferenciam. Países como a Austrália, Canadá, Suécia, dentre outros, têm tentado minimizar esses desafios nos seus planos pedagógicos 5 ,18-20

Outro resultado apresentado neste estudo foi a pequena relação encontrada entre as três categorias (competências esperadas, ações realizadas no cuidado nutricional e operacionalização do curso). É possível sugerir que os conteúdos dos projetos político-pedagógicos estão diferenciados pelo quanto estão assimilados aos conteúdos da primeira classe (tratamento) e da segunda classe (prevenção e promoção). Ou seja, a segunda classe remete a objetivos e competências associadas à prevenção e promoção de saúde, enquanto a primeira remete ao tratamento, traduzindo nos resultados os diferentes níveis de atenção à saúde, bem como a relação desses níveis com o curso de Nutrição no que diz respeito aos conteúdos veiculados nos projetos político-pedagógicos.

Essa tem sido uma das grandes dificuldades das profissões que envolvem a atenção à saúde. Associar as informações epidemiológicas locais, nacionais e/ou internacionais dos riscos à saúde e conciliá-las com a promoção, prevenção e tratamento ${ }^{20}$. Estes temas têm sido considerados desafios também em nível internacional e têm mobilizado a comunidade acadêmica e científica no sentido de problematizar novas abordagens no processo de ensino-aprendizagem e na articulação de conhecimentos e ações que permitam aos profissionais responder a demandas de complexidade crescente ${ }^{19,20}$.

Ao analisar os avanços das Diretrizes Curriculares Nacionais em relação ao currículo mínimo, Soares \& Aguiar ${ }^{21}$ destacam que permanece a inclinação à concepção epidemiológica e clínica da atenção à saúde, voltada para o tratamento. Costa $^{22}$, estudando o processo de formação do nutricionista no Brasil, verificou, nos currículos dos cursos, a desarticulação e desconexão entre os conteúdos do ciclo básico e do ciclo profissional. Tal fato, por sua vez, dificulta a integração de conhecimentos exigidos no momento da prática profissional. Amorim et al. ${ }^{23}$ chamam a atenção para o predomínio do modelo biológico cartesiano na formação dos nutricionistas, que privilegia a abordagem individual, centrada no processo curativo, no tratamento hospitalar e no paradigma flexneriano de assistência médica ${ }^{24}$. O predomínio desse modelo repercute na atuação, dificultando a integralidade e a melhor compreensão dos determinantes do processo saúde-doença, em especial aqueles não biomédicos. Dessa maneira, os autores salientam a necessidade dos cursos de Nutrição se preocuparem com a proposta de um plano pedagógico que conduza à superação do paradigma cartesiano, onde se privilegia o tra- 
tamento em detrimento da prevenção e da promoção ${ }^{23}$.

No que diz respeito aos planos de ensino das disciplinas da área de saúde coletiva, observa-se que avaliação nutricional, clínica e dietoterapia no curso da vida, torna-se bastante específica e dissociada de outras temáticas, como: epidemiologia nutricional e vigilância em saúde; educação nutricional e comunicação; formação para atuação profissional; aspectos culturais e ciências sociais, políticas públicas, definidores das demais classes. Dessa maneira, o "hiato entre o biológico e o social" descrito por Costa22 está evidente nos currículos.

A falta de mecanismos concretos para a articulação entre os conhecimentos biológicos e sociais se mantém frente à deficiência de uma reflexão, e, principalmente, de uma atitude referente à prática profissional e à totalidade social. Essas considerações vêm ao encontro da argumentação de Fávero ${ }^{25}$ e de Amorim et al. ${ }^{23}$ de que os cursos de graduação deveriam trabalhar seus currículos de maneira articulada e integrada durante toda a formação profissional. Soares \& Aguiar $^{21}$, ao analisarem os avanços das Diretrizes Curriculares Nacionais em relação ao currículo mínimo, destacam que permanece inalcançada a dimensão da cultura e dos aspectos históricos e políticos, dentre outros, no que se refere ao estudo dos alimentos e da alimentação e, ainda, à sua interação. Apesar de haver iniciativas de mudanças no perfil profissional e de propostas de reformas curriculares ${ }^{1,21,26-28}$, indo ao encontro das sugestões propostas pelas Diretrizes Curriculares Nacionais do curso de graduação em Nutrição ${ }^{29}$, tal mudança não foi identificada nos projetos político-pedagógicos e nos planos de ensino de disciplinas analisados.

Com a articulação entre conteúdos e disciplinas, o futuro profissional poderá se tornar capaz de analisar e enfrentar as principais questões de alimentação e nutrição em saúde coletiva, uma vez que as atitudes adotadas profissionalmente são o reflexo da formação e das experiências práticas $^{30}$. Além disso, as disciplinas devem viabi- lizar uma proposta curricular que inclua temas que possibilitem aos estudantes vivenciar situações que transponham barreiras disciplinares, superando a dicotomia das áreas biológicas e humanas, diagnóstico e prática, colocando-as em diálogo. Isso vai ao encontro de uma proposta interdisciplinar no ensino, extensão e pesquisa ${ }^{31}$. Dessa maneira, a articulação interdisciplinar é essencial para que o estudante adquira as competências necessárias para atuar no âmbito da saúde coletiva7,8.

\section{O N CLUSÃO}

A distância entre os conteúdos, presente na estrutura dos projetos político-pedagógicos e dos planos de ensino analisados, indica uma dicotomia ao se descreverem os objetivos, habilidades e competências pretendidas, conteúdo, organização de cada disciplina e prática profissional. Além disso, há ainda uma separação -, mesmo na área de saúde coletiva - entre os elementos biológicos, as práticas sociais e a formação promovida pelos atuais currículos de Nutrição.

Dessa maneira, deflagrar algumas reflexões sobre a estrutura dos projetos político-pedagógicos e sobre os planos de ensino das disciplinas em saúde coletiva implica repensar a construção do conhecimento em Nutrição, uma vez que se trata de saberes predominantemente transversais e interdisciplinares que circunscrevem o campo da alimentação e nutrição.

As limitações do presente ensaio sugerem que novos estudos sejam realizados, englobando mais instituições do ensino superior em Nutrição e analisando os currículos e modelos de ensino predominantes, ao mesmo tempo que se investiguem os resultados e o impacto de processos de renovação curricular que estão sendo implementados por todo o país.

\section{A GRADECIMENTOS}

Á participação na concepção do estudo de Natacha Toral Bertolin e a revisão versão preliminar de Renata Gomes Falcão. 


\section{COLABORADORES}

E RECINE participou da concepção e desenho do projeto, pesquisa de literatura, interpretação dos resultados, redação e revisão final do artigo. A SUGAI participou da pesquisa de literatura, interpretação dos resultados, redação e revisão final do artigo. RA MONTEIRO participou da concepção e desenho do projeto, análise e interpretação dos resultados e redação do artigo. A RIZZOLO participou da concepção e desenho do projeto e redação do artigo. A FAGUNDES participou da elaboração do instrumento de coleta, coleta, montagem do banco de dados, análise e interpretação dos resultados.

\section{REFERÊ NCIAS}

1. Vasconcelos FAG, Batista Filho M. História do campo da Alimentação e Nutrição em Saúde Coletiva no Brasil. Cienc Saúde Colet. 2011; 16(1):81-90. doi: 10.1590/S1413-8123201100010 0012

2. Freitas MDCS, Minayo MCDS, Fontes GAV. Sobre o campo da Alimentação e Nutrição na perspectiva das teorias compreensivas. Ciênc Saúde Colet. 2011; 16(1):31-8.

3. Bosi MLM, Prado SD. O campo da Alimentação e Nutrição em Saúde Coletiva: identificando contornos e projetando caminhos. Ciênc Saúde Colet. 2011; 16(1):4.

4. Jonsdottir S, Thorsdottir I, Kugelberg S, Yngve A, Kennedy NP, Hughes R. Core functions for the public health nutrition workforce in Europe: $A$ consensus study. Public Health Nutr. 2012; 15(11):1999-2004.

5. Kugelberg S, Jonsdottir S, Faxelid E, Jönsson K, Fox A, Thorsdottir I, et al. Public health nutrition development in seven European countries: Cosntraining and enabling factors. Public Health Nutr. 2011; 15(11):1989-98.

6. Shrimpton R, Hughes R, Recine E, Manson JB, Sanders D, Marks GC, et al. Nutrition capacity development: A practice framework. Public Health Nutr. 2013; 1(1):1-7.

7. Hughes R. Public health nutrition workforce composition, core functions, competencies and capacity: Perspectives of advanced-level practitioners in Australia. Public Health Nutr. 2003; 6(6):607-13. doi: 101079/PHN2003465

8. Recine E, Sugai A. Consenso sobre habilidades e competências do nutricionista no âmbito da saúde coletiva. Brasília: Observatório de Políticas de Segurança Alimentar e Nutrição; 2013.

9. Recine E, Gomes RCF, Fagundes AA, Pinheiro ARO, Teixeira BA, Sousa JS, et al. A formação em saúde pública nos cursos de graduação de Nutrição no Brasil. Rev Nutr. 2012; 25(1):21-33. doi: 10.1590/ S1415-52732012000100003

10. Reinert M. Manuel d'utilisation Alceste. Version 4.7 pour Windows edition. Tolouse: Image; 1986.

11. Kronberger N, Wagner W. Palavras-chave em contexto: analise estatistica de textos. In: Bauer MW, Gaskell G, editor. Pesquisa qualitativa com texto, imagem e som: um manual prático. $9^{a}$ ed. Rio de Janeiro: Vozes; 2011. p.416-42.

12. Azevedo DM, Costa RKS, Miranda FAN. Uso do Alceste na análise de dados qualitativos: constribuições na pesquisa de enfermagem. Rev Enferm UFPE. 2013; 7(Esp. 201):5015-22. doi: 10.5205/ reuol.4700-39563-1

13. Moscovici S. Representações sociais: investigações em psicologia social. 6a ed. Petrópolis: Vozes; 2009.

14. Camargo V. ALCESTE: um programa informático de análise quantitativa de dados textuais. In: Moreira A, organizador. Perspectivas teórico-metodológicas em representações sociais. João Pessoa: Editora Universitária; 2005. p.511-39.

15. Soares C. Em torno do pensamento social e do conhecimento do senso comum. A aplicação da metodologia Alceste em contextos discursivos distintos. In: Moreira A, organizador. Perspectivas teórico-metodológicas em representações sociais. João Pessoa: Editora Universitária; 2005. p.541-68.

16. Bauer MW, Aarts B. A construção do corpus: um princípio para a coleta de dados qualitativos. In: Bauer MW, Gaskell G, editor. Pesquisa qualitativa com texto, imagem e som: um manual prático. $9^{a}$ ed. Rio de Janeiro: Vozes; 2011. p.39-61.

17. Azevedo DM, Miranda FAN. Teoria das representações sociais e Alceste: contribuições teórico-metodológicas na pesquisa qualitativa. Saúde Trans Social. 2012; 3(4):4-10.

18. Hughes $R$, Margetts $B$. The public health nutrition intervention management bi-cycle: A model for training and practice improvement. Public Health Nutr. 2011; 15(11):1981-8.

19. Shrimpton R, Hughes R, Recine E, Mason JB, Sanders D, Marks GC, et al. Nutrition capacity development: A practice framework. Public Health Nutr. 2013; 17(3):682-8. doi: 10.1017/S13689800 13001213

20. Frenk J, Chen L, Bhutta ZA, Cohen J, Crisp N, Evans $T$, et al. Health professionals for a new century: Transforming education to strengthen health systems in an interdependent world. Lancet. 2010; 
376(9756):1923-58. doi: 10.1016/S0140-6736(10) 61854-5

21. Soares NT, Aguiar AC. Diretrizes curriculares nacionais para os cursos de Nutrição: avanços, lacunas, ambiguidades e perspectivas. Rev Nutr. 2010; 23(5):895-905. doi: 10.1590/\$1415-52732010000 500019

22. Costa NMSC. Revisitando os estudos e eventos sobre a formação do nutricionista no Brasil. Rev Nutr. 1999; 12(1):5-19. doi: 10.1590/\$1415-52731999 000100001

23. Amorim STSP, Moreira H, Carraro TE. A formação de pediatras e nutricionistas: a dimensão humana. Rev Nutr. 2001; 14(1):111-8. doi: 10.1590/S1415-5 2732001000200004

24. Medeiros MAT, Amparo-Santos L, Domene SMA. Education of dietitian's in Brazil: Minimum clock hours of instruction for a bachelor's degree in nutrition. Rev Nutr. 2013; 26(4):583-93. doi: 10.15 90/S1415-52732013000500009

25. Fávero ML. A Universidade e estágio curricular: subsídios para discussão. In: Alves N, organizador. Formação de professores: pensar e fazer. Coleção Questões Nossa Época. 2a ed. São Paulo: Cortez; 1993. p.103.

26. Santos LAS, Silva MCM, Santos JM, Assunção MP, Portela ML, Soares MD, et al. Projeto pedagógico do programa de graduação em nutrição da Escola de Nutrição da Universidade Federal da Bahia: uma proposta em construção. Rev Nutr. 2005; 18(1):105-17. doi: 10.1590/S1415-527320050001 00010

27. Vasconcelos FAG. O nutricionista no Brasil: uma análise histórica. Rev Nutr. 2002; 15(2):127-38. doi: 10.1590/S1415-52732002000200001

28. Costa NMSC. Formação pedagógica de professores de nutrição: uma omissão consentida? Rev Nutr. 2009; 22(1):97-104. doi: 10.1590/\$1415-52732009 000100009

29. Brasil. Ministério da Educação. Institui diretrizes curriculares nacionais do curso de graduação em nutrição. Resolução CNE/CES n ${ }^{\circ}$ 5, de 7 de novembro de 2001. Diário Oficial da União. 2001; Seção 1. p.39.

30. Hughes R. A socio-ecological analysis of the determinants of national public health nutrition workforce capacity: Australia as a case study. Fam Community Health. 2006; 29(1):55-67.

31. Canesqui A, RWD G. Antropologia e nutrição: um diálogo possível. Rio de Janeiro: Fiocruz; 2005.

Recebido em: 7/5/2014 Versão final em: 11/9/2014 Aprovado em: 28/10/2014 